\title{
Mobile Virtual Reality to Develop a Virtual Laboratorium for the Subject of Digital Engineering
}

\author{
https://doi.org/10.3991/ijim.v13i04.10522 \\ M. Khairudin $\left.{ }^{\bowtie}\right)$, A.K. Triatmaja, Istanto W.J. \\ Universitas Negeri Yogyakarta, Indonesia \\ moh_khairudin@uny.ac.id \\ M.N.A Azman \\ Universiti Pendidikan, Perak, Malaysia
}

\begin{abstract}
This paper provides development of a virtual laboratorium for the subject of digital engineering. The virtual digital engineering laboratory based on mobile virtual reality is a finding that can be used for replacing a real laboratory. Using a virtual laboratory can be conducted a learning and teaching process at anytime and anywhere as long as it has an android device. This study applies a virtual laboratory to mobile virtual reality for a virtual digital engineering laboratory. The results of this study were functional application software to learn how to apply a virtual digital engineering laboratory through mobile virtual reality technology. A lot of components and circuits of logic gate can be simulated in this virtual laboratorium. This study presents a simple Android-based virtual tools for the visualization and investigation in real time of circuits of logic gates without signal disturbances. The package can be used as an educational tool in various lectures or homework to aid teaching digital engineering theory or practically.
\end{abstract}

Keywords - Virtual laboratorium, virtual reality, mobile, digital engineering

\section{Introduction}

Open Laboratory usually used for learning program by student in school. The construction of laboratories requires careful planning and substantial funding. Laboratories requirementsare vary according to the function of its aim. Laboratories that have been established permanent will require a lot of time to remodel its function.

Each laboratories need rules for using goods and monitoring regularly for the safety. Work accidental happen on laboratory can disturb laboratory activities. It needs a long time to repair the building and the tools. Some of the tools must be changed and cannot repair too if there are serious damage. To support the limited number of facilities in the real laboratory, then a breakthrough in simulation technology is needed before students conducted a real practices in the real laboratorium. Especially simulation technology through smartphone [1]. 
Smartphone on this era is one of the primary needs for people. It is also use for communicate without any obstacle. Operating System (OS) for smartphone mostly use Android. OS android support a lot free applications. Most of the developers also make applications for OS android because people like to use it.

An alternative technology that can apply for future android applications is a Virtual Reality (VR). There are many using of Virtual Reality on game devices and support by Virtual Reality glasses and Controller. Virtual Reality is technology which this device can show goods as in reality. Using a Virtual Reality on laboratory can increase safety and easiness on laboratory activities.

One of the competencies needed in this digitalization era is subject of digital engineering. The digitalengineering is good competition skill to face up Industrial Era 4.0. Digital data and communicate are most of component use on this era. Knowledge about digital engineering is base of programming and developing from machines on this era.

Almarshoud[2] shows a laboratory model, namely a remote laboratory. Remote laboratory also was known as online laboratory name. One of the online laboratories in electrical engineering is the electronics laboratory. Which online laboratories provide knowledge to students with concepts and capabilities to practice with longer time using online laboratories. These advantages are similar to the use of virtual laboratories that can be used anytime and anywhere. But in conventional laboratories can provide the ability to overcome problems and the ability to cooperate with students.

Mekonnen[3] describes the characteristics of laboratory management must have five references namely simple, measurable, achievable, relevant, time bound (SMART). SMART is needed for development and application of virtual laboratories. Because laboratory management can improve the quality of the virtual laboratory. The quality of the laboratory is defined as accuracy, reliability, and continuous test results [4].

WHO [4] also shows 12 quality systems from laboratory management, that are organization, personnel, equipment, purchasing and inventory, process control, information management, document and record, occurrence management, assessment, process improvement, customer service, facilities and safety. These systems can be used in the development and application of virtual laboratories to determine laboratory quality.

Bureau [5] describes the security management system in the laboratory must be monitored in accordance with the standards of laboratory safety and prepare for emergency needs. In conventional laboratories, technicians are required to always maintain security in the laboratory. Safety in the laboratory is very important that must be maintained so that laboratory use becomes more effective [6] and [7].

Persson et al. [8] explained about mobile technology used in mobile learning. The concept of mobile learning has five characteristics, these are probability, accessibility, personalization, connectivity, and can increase learning motivation. These characteristics are similar to the characteristics of a virtual laboratory because the use of virtual laboratories that are applied is also based on mobile.

Zhang et al. [9] and [10]described that Virtual Reality is defined as a computer simulation of a $3 \mathrm{D}$ environment where users can interact by looking at physical objects as in reality by using special equipment, such as helmets with screens on the inside and 
gloves with sensors. There are several categories of VR, namely VR, Immersive VR, distributed VR, and augmented VR desktops.

Odeh et al. [11] and [12] explained the advantages of virtual laboratories, which are easy to use, easy to understand the concept of theory, available a lot of time, satisfying the theory of knowledge, a safe environment, advancing new skills, driven by group cooperation, a comfortable place, and more time to experiment.

Lixia et al. [13] explained that there are six characteristics that must be followed in the preparation of virtual laboratories, which include

- Physical characteristics of virtual laboratory equipment must be consistent with equipment in real-world laboratories

- Ability to become higher interactive learning

- Ability to provide real-time feedback

- Functions in using tools

- Virtual display is similar to the actual environment

- Virtual display is a scene that can be changed according to needs such as reducing, enlarging, and browsing

Jaya [14] explains that there are advantages of virtual reality that are used as virtual laboratories which include virtual environments that can save budget rather than physical environments, virtual environments are safer than physical environments, interactions through virtual environments provide certain experiences that are not obtained in the physical environment, practice in the virtual environment can be more developed than the physical environment, the concept of learning from the experience experienced by users directly, virtual environments give a real impression that resembles the physical environment. Virtual laboratories can increase student motivation in terms of task value and self-efficacy [15].

Ogungbenro et al. [16] explained some of the advantages of using emulators on digital techniques, namely the original appearance, nuances and behavior of digital objects are maintained, the initial capital on emulator production is greater but other expenditures will be more efficient, reducing laboratory usage time, many emulators have been developed well and licensed, emulators can be used on variety of device systems, the physical needs of emulators can be reduced so that they can reduce costs and practice time, most emulators have large data memory and can provide many simulated electronic components.

This study conducted a virtual laboratory development for the field of digital engineering. With the development of this digital virtual laboratory, the calculation of the physical cost of procurement of laboratories can be reduced, because it has been replaced in the virtual laboratory. Likewise, health and safety in all laboratory activities will be easily achieved because all laboratory activities are carried out virtually. 


\section{Designing a Virtual Laboratory for the Subject of Digital Engineering}

This study produces a virtual laboratory to the subject of digital engineering. The virtual laboratory shows a set of room that consists of a lot of computer and mebeulerequipment namely tables, chairs and also cupboard shelfthat presented in virtual. Also consists of a lot of computers and electronics components namely integrated circuits of logic gates for practices learning in laboratory in virtual.

\subsection{Virtual laboratory design}

Virtual laboratories are compiled using mobile virtual reality technology. Virtual laboratories are made to resemble actual conventional laboratories. Controls of virtual lab movements use Bluetooth remote that is set to be able to execute commands in the virtual laboratory. In the virtual laboratory, there are several choices that can be done by the user. In order to know the basics of the theory of logic gate. Then there are also simulations from the logic gate and simulation of the logic gate circuit. Figure 1 presents the flowchart of virtual laboratory.

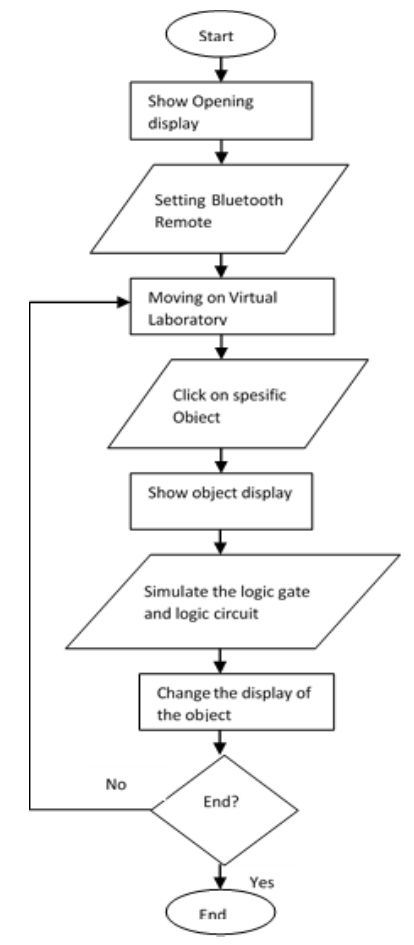

Fig. 1. Virtual Laboratory Flowchart 


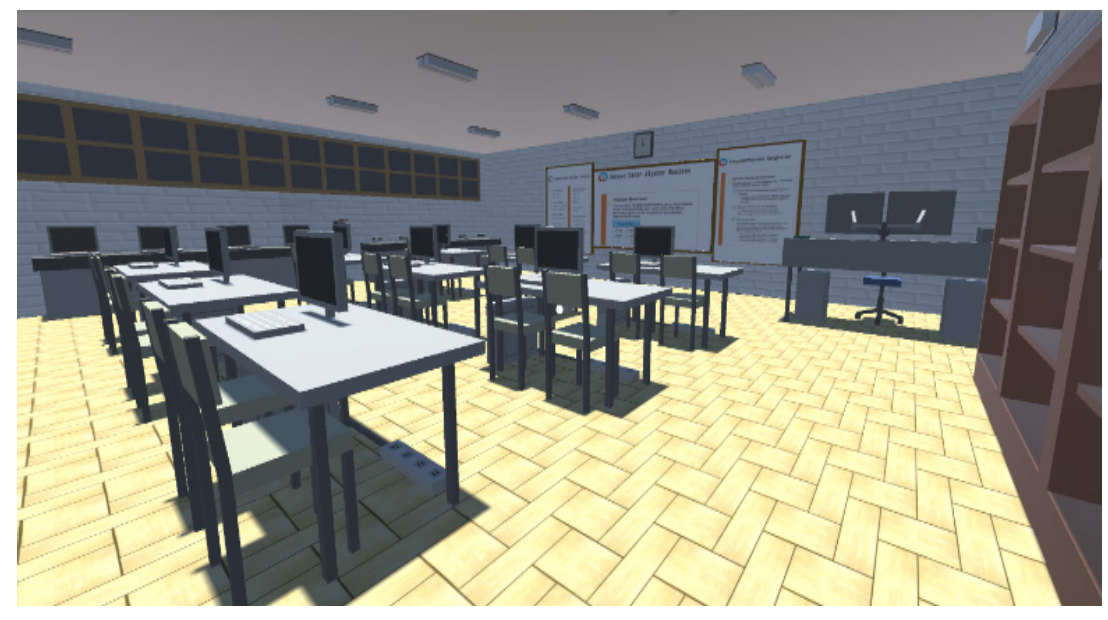

Fig. 2. Display of laboratory virtual space

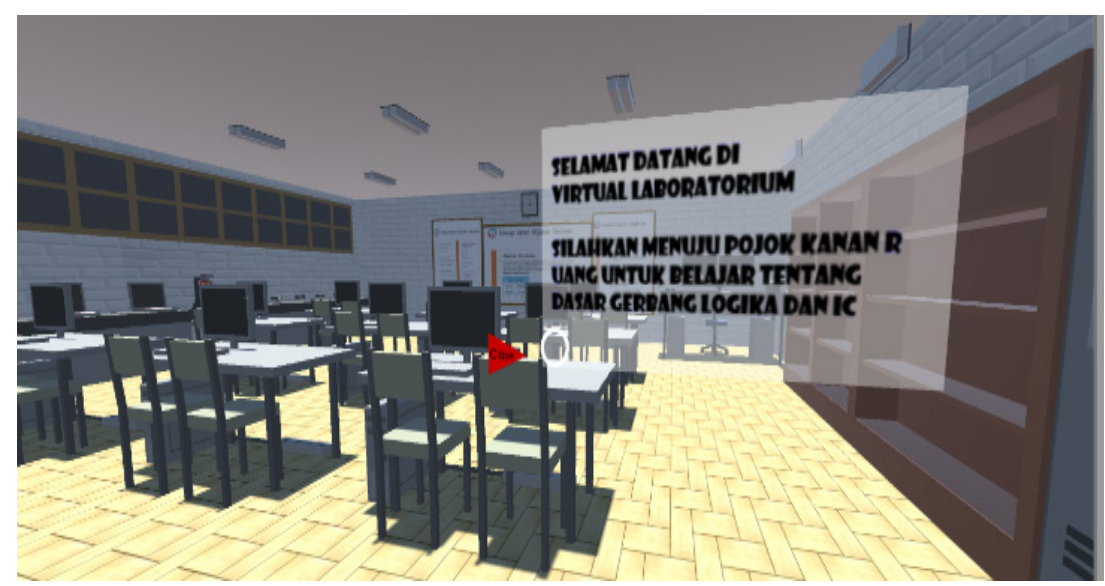

Fig. 3. The initial appearance of the virtual laboratory

Figure 1explains that when a virtual laboratory digital technique is run, an opening screen will appear showing the first thing that can be done in the virtual laboratory. In the first view, there will be a box-shaped display with the initial command in the use of a virtual laboratory. The sentence on the display is in the form of a command to move towards a certain area and start using a virtual laboratory. The first command is to move to the corner of the room and click on the IC so that the display and certain commands appear. The purpose of the command is to make users adapt to digital engineering virtual laboratories so that it will be easy to operate the digital engineering laboratory's virtual applications.

In the second part of the flowchart after the main display appears, the user has not been able to use the command to run on a virtual engineering digital laboratory. Users are asked to set up a Bluetooth remote that has been provided. There are several stages 
in setting up a Bluetooth remote. The first is setting up the Bluetooth remote by first activating the bluetooth remote provided by giving the battery and pressing the power button for a long time. When this process the light indicator on the bluetooth remote will light up flashing which indicates that the bluetooth remote is waiting to be connected to an android device. The next step that must be set is Bluetooth on Android devices, this is done by activating Bluetooth on Android and pairing or connecting from an Android device to a Bluetooth remote device.

After performing the pairing stage on the bluetooth remote, the indicator light on the bluetooth remote that previously lights up blinking will indicate that the bluetooth remote is ready to be used. At this stage the bluetooth remote is connected, but it cannot be used to run on a digital laboratory. Calibration on bluetooth remote is needed to change the mode of the bluetooth remote so that the user can move in the virtual laboratory. The calibration is done by pressing the @ $+\mathrm{C}$ button. After pressing the button, the remote bluetooth device can be connected to an Android device and can be used to move to a digital engineering virtual laboratory. The feature is that the bluetooth remote has been calibrated and is ready to be used in a digital engineering virtual laboratory. The cursor appears when the analog direction on the bluetooth remote is moved.

After the calibration circuit on the remote bluetooth is complete, the user can walk or move on the digital engineering virtual laboratory. Users when using the virtual laboratory mode when the user moves the analog button on the bluetooth remote, the user will be able to move in the direction of the bluetooth remote button when directed in a certain direction. In a move the user cannot pass solid objects in the virtual laboratory technique. This is adjusted to the characteristics of objects in the real world.

\subsection{Implelmentation of the circuit of logic gates in virtual laboratory}

The next stage of the flowchart is that the user can give commands to certain objects in the digital laboratory's digital technique. The command given will appear when clicking on the bluetooth remote or when the screen is pressed. Characteristics of objects in a virtual laboratory digital technique has a certain command is when the object is in the midpoint then the midpoint will turn into a circle that indicates that the object is ready to be given a command so that it can bring up a certain display. There are several objects that can be governed in a virtual engineering digital laboratory, these objects, among others, ICs that can bring up the properties and characteristics of logic gates, laptops that are able to display a simulation display of each particular logic gate according to the instructions on the laptop, and computer provide a simulation of a more complex set of logic gates based on Boolean algebra.

In the simulation phase, it can be raised when giving commands to a laptop or computer in a digital engineering virtual laboratory. The simulation that can be done is in the form of a logic gate simulation by giving input between 0 or 1 and automatically the output will appear according to the logic of the logic gate. In addition to logic gate simulation, computers on each table have various types of more complex logic gate circuits with the same working system with logic gate simulations, which provide input to the circuit so that certain results can emerge according to the logic and truth of the gate circuit that logic. 
The next step before the last stage is that the user is given the flexibility to change the appearance or input of the simulation in the digital engineering virtual laboratory by pressing the button on the bluetooth remote so that it can change input in all simulations to 0 or 1 . Users can also replace the logic gate simulation exist when doing logic gate simulations. The logic gate simulation that can be replaced is AND with OR, then NAND with NOR. When finished using a digital laboratory, the user only presses the close or back button on the smartphone screen and if the user still wants to use a virtual laboratory digital technique, the user only needs to explore the untested parts of the virtual laboratory.

This is a stage in the development of a digital engineering laboratory. The use of virtual laboratories based on these stages requires certain time and certain preparation to be able to use them at the level of an institution or school. Virtual laboratories also need supporting equipment to support virtual digital engineering laboratories that can be applied properly and in accordance with the standards and conditions as well as conformity to certain learning materials.

\section{$3 \quad$ Results and Discussions}

This study develops virtual laboratory for the subject of digital engineering. The profiles of virtual laboratory present a set of room that consists of a lot of computer and mebeuler equipment namely tables, chairs and also cupboard shelfthat presented in virtual. Also consists of a lot of computers and electronics components namely integrated circuits of logic gates for practices learning in laboratory in virtual.

Virtual Laboratory Display

Figure 2 shows the display space of a digital engineering virtual laboratory. There are various objects that can be used applicatively and can display other displays such as simulations of logic gates in digital techniques. In a virtual laboratory it is designed and developed to resemble real objects. In the virtual laboratory there are many components of objects such as ceramics, tables, chairs, computers, laptops, whiteboards, ICs, and lights so that when users use a virtual laboratory of digital techniques, the user is given the same scenery as the real world numbered (sub)section headings.

Figure 2 exposes objects in the virtual laboratory to have the same characteristics and properties as objects in the real world, such as table and chairs that have hard and not easily traversed properties, so that in virtual laboratories these objects are also impassable and not penetrated when the user move in a certain direction past the object.

In the virtual laboratory digital engineering also has sufficient lighting to carry out the practice as well as in conventional laboratories. There are also shadows of objects so that the objects look like real and these objects also have the same properties in the real world. The layout of objects in the virtual laboratory is also adapted to ergonomics that are in accordance with the Occupational Health and Safety standard so users can find out how the layout should be in a digital engineering laboratory. In the virtual laboratory digital techniques also have a preliminary display that gives us commands for things that can be done first. This command can be seen in Figure 3. 
Virtual laboratories also have a display similar to real-world objects but still look like visual objects. The use of virtual digital engineering laboratories is adapted to laboratory standards used in the real world. The use of virtual laboratory digital techniques is also used as an effort to conserve the construction of an original laboratory because in the virtual laboratory the addition of components or equipment in the virtual laboratory can be done quickly and without having to spend extra. The addition of equipment in a virtual laboratory digital technique is done by designing virtual shapes of objects from the real world which are then transformed in virtual form and 3D forms. After the shape of the original object has been converted into 3D in visual form, coloring is adjusted to the color of objects in the real world. This is done to get a virtual form that has similarities with real objects.

After the design stage of a real object into a virtual object is complete, these objects can be included in the virtual laboratory digital technique as one of the tools that can be used and utilized in a virtual laboratory. Objects that are included in the virtual laboratory have certain functions that can give the same impression and function to objects found in the real world. Lighting on the virtual laboratory is installed above, this is likened to a lamp that illuminates the laboratory in the real world. The light in this virtual laboratory digital technique can produce a shadow of solid objects around in accordance with the position of the lamp. There are also a number of cabinets and shelves that can later be developed with a variety of equipment that can support the practical process in digital engineering virtual laboratories.

\subsection{Virtual laboratory implementation}

The next steps after completed design and development are implementation of virtual laboratory for the learning.

Equipment and Virtual Laboratory Devices: The equipment used for the development and implementation of virtual laboratories includes VR boxes, VR Controllers, Android Smartphones (XiaomiRedmi 4X), Laptops, Unity3D software and Virtual Laboratorium.apk.

Virtual laboratories were developed using the Unity3D pang application done with a laptop. Virtual laboratories use virtual reality technology that runs on smartphone Android devices. The application generated from programming in Unity3D is a Virtual Laboratory. For supporting equipment from a virtual laboratory, VR boxes are installed such as using glasses and VR Controllers which are used as drivers when running a virtual laboratory. Here is the VR box fan VR Controller in Figure 4. 


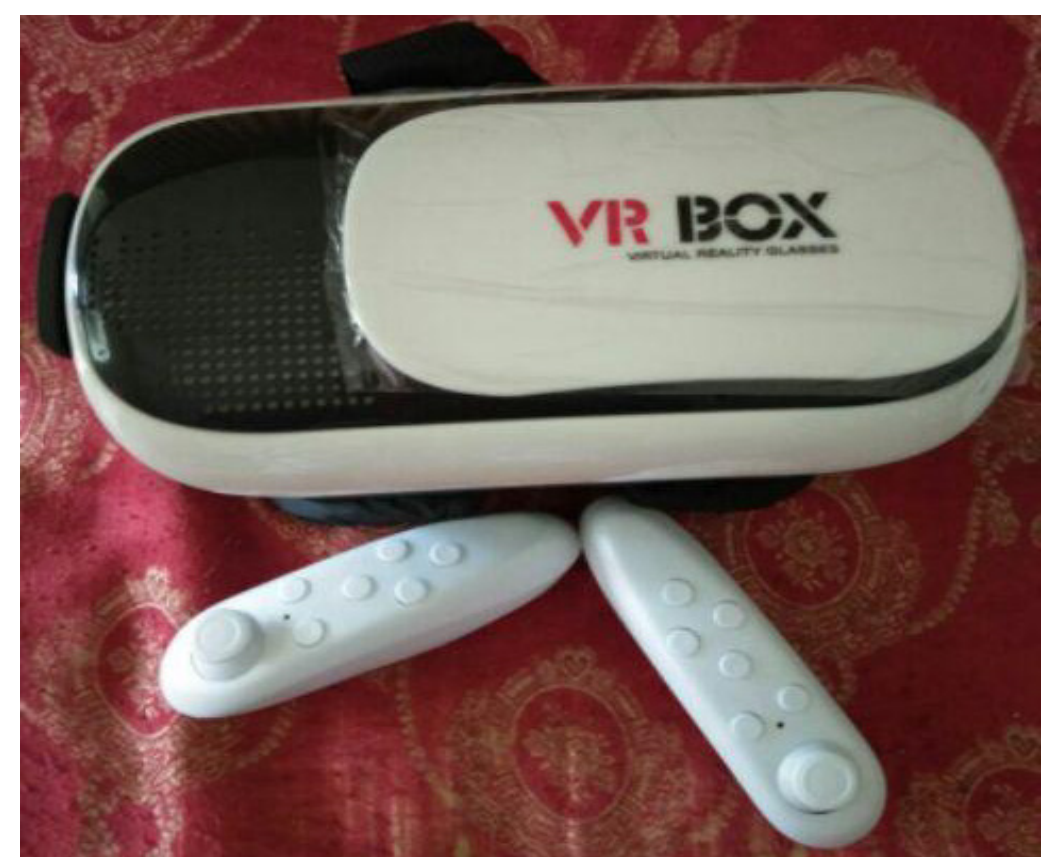

Fig. 4. VR box and VR controller

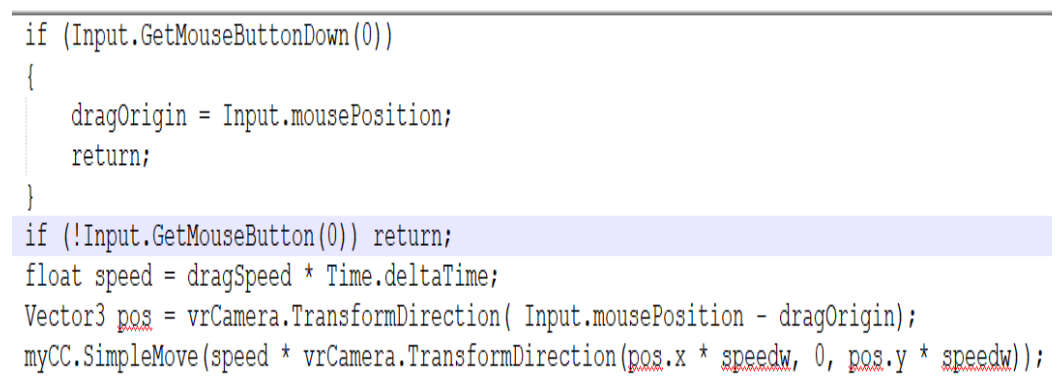

Fig. 5. Drive program with Bluetooth Remote

The equipment in this digital laboratory is tailored to the needs and equipment of laboratory needs in the real world. The use of VR Box can support the form of a virtual laboratory so that it can produce a real impression on a virtual laboratory of digital engineering. In using the VR Box, users only need to move their heads to find out the surroundings of the virtual laboratory. It must also be supported with an appropriate android device and has a position sensor. The position sensor on an android device is used to determine the direction of the head so that our vision can change according to the direction of the eye we are headed.

The equipment must also be supported by equipment to move to certain places in the digital laboratory of digital engineering. The movement can be done using a Bluetooth remote with a one-hand remote specification using Bluetooth communication that can 
control the screen of a smartphone device and a digital engineering laboratory virtual application. In the bluetooth remote has 2 buttons in front that function as the OK and Cancel buttons on the smartphone device. There are also analog buttons that can be directed 360 degrees which function as movers of the main characters or characters that are seen heading to certain places.

There are 6 other buttons, each of which has a different function. One button functions as a power button from a digital virtual lab, 1 button is used as a remote modifier, this button is @. There are also 4 other buttons that have different functions. Each button has its own mode when pressed together with the @ key. Each function of the button is on the A button used to convert the remote into a drive on VR with horizontal control, the $\mathrm{B}$ button is used to change the bluetooth remote into a voice and camera converter. The $\mathrm{C}$ key functions as a control of a virtual laboratory with vertical controls. And the $\mathrm{D}$ button will bring up the cursor like a mouse cursor that can be used properly using the mouse.

Gesture in Virtual Laboratory: Several the movements that can be done in a virtual laboratory include: (1) Drive Control - to move as if the user is walking in various directions. Drive control uses the button function on the VR controller. The button used to move is the mouse pad on the VR controller. The following Figure 5 shows the program that used the movement pattern that was carried out.

The drive control-reading program is done by detecting analog values on the bluetooth remote and changing the display in the virtual laboratory so that it shows as if it can move to a certain place. The ability to detect analog valueson a bluetooth remote can be read by using existing bluetooth communication and reading the analog analog value up or down with different positive and negative values. Direction reading based on analog values sent on bluetooth remote. Next, is the flowchart using Bluetooth remote as a driver in the virtual laboratory? Figure 6 shows Flow Chart Use of Drive Control.

The working system on the drive control is started from reading the cursor value on the bluetooth remote. To read data from a Bluetooth remote, it is necessary to connect the connection between the Bluetooth remote and Android first. Then when it has entered the application, the cursor button movement will be moved and will be followed by movement in the virtual laboratory. Each cursor movement on a remote bluetooth is divided into two directions, namely $\mathrm{X}$ and $\mathrm{Y}$. each direction has a certain value that has a value above 0 and below 0 . This value determines the forward or backward movement or the right and left movements to match the cursor.

The movement on the cursor changes the coordinate value from the initial position so that movement in the virtual laboratory follows the direction of the cursor movement.

If the reading on the remote bluetooth cursor upwards it will give a $\mathrm{Y}+$ value so that the command coordinates will move forward, and vice versa if the bluetooth remote is directed down then the $\mathrm{Y}$ value - on the remote will give a command to the virtual laboratory to backward. While for the right and left on the bluetooth remote can move the right and left direction on the bluetooth remote will give the value $\mathrm{X}+$ or $\mathrm{X}$ - so it will change the coordinates of the display to the right or left. 


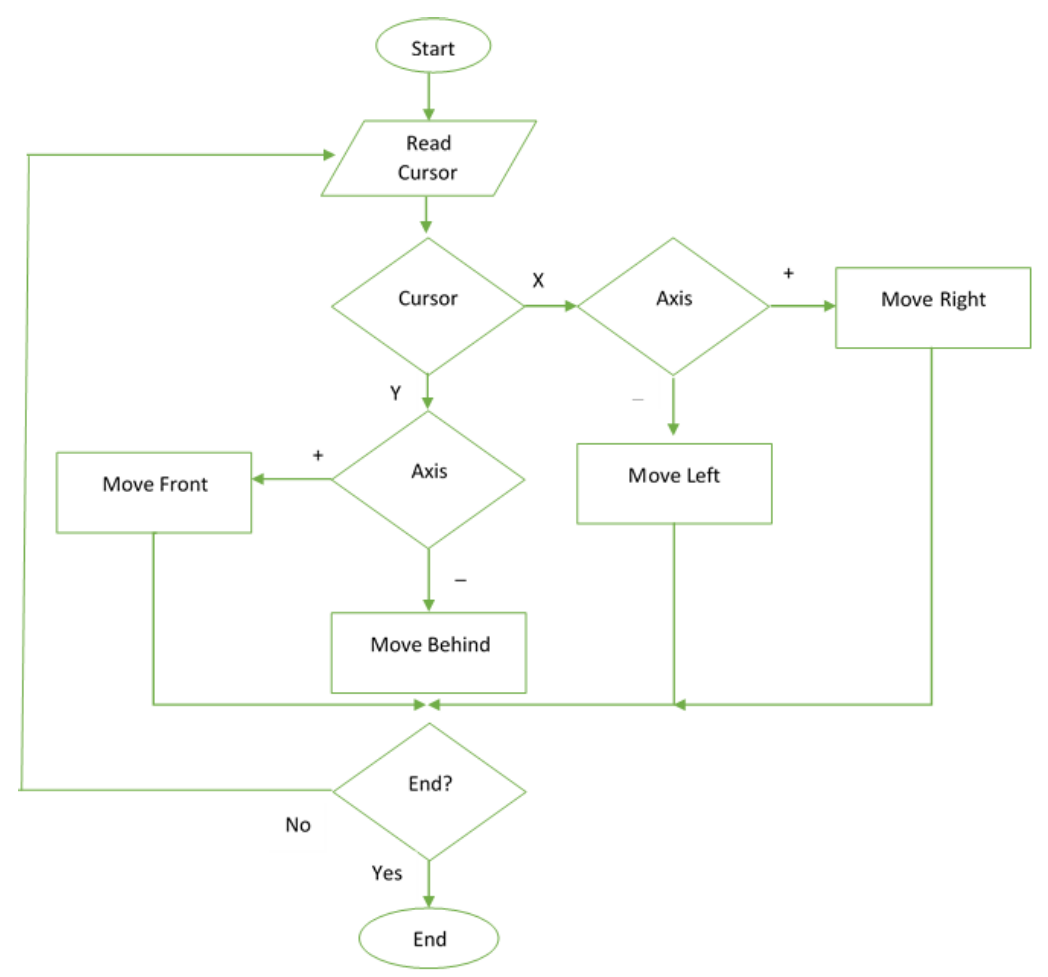

Fig. 6. Flow Chart Use of Drive Control

The second is Visual Control - To move the visual in the direction of the eye in seeing. In visual control of vision is moved according to the position of the head we are facing. Visual control of reading the value of the gyro sensor and accelerometer on an android device. Programming on Unity3D has a feature to replace the movement of vision into a gyro sensor reading on Android. This feature will be displayed in Figure 7. The following is a program that is used as visual control of the virtual laboratory.

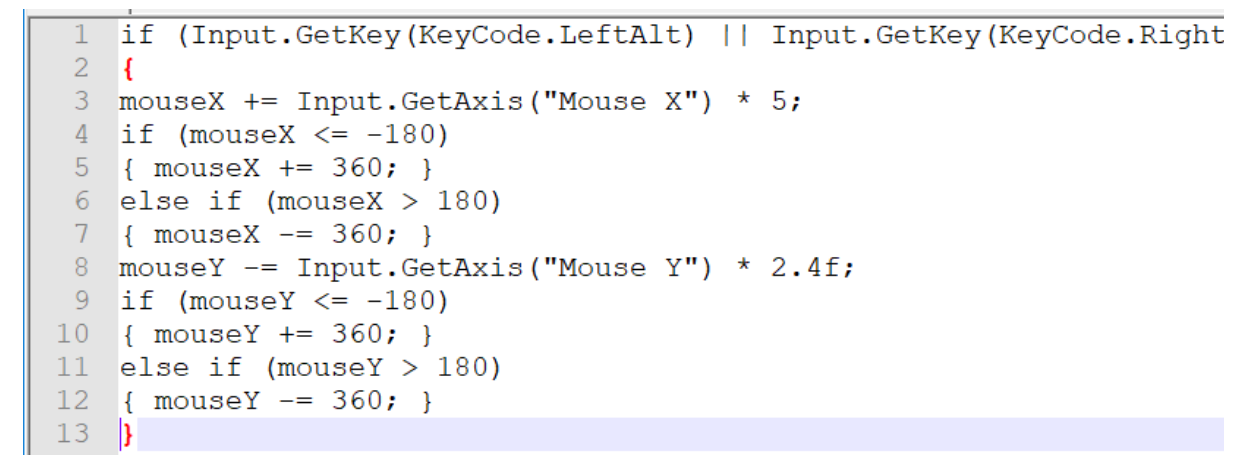

Fig. 7. Program for Viewing Control 


\begin{tabular}{|c|c|c|c|c|c|}
\hline Android & $\Leftrightarrow$ & \multirow{6}{*}{$\begin{array}{l}\text { Texture Compression } \\
\text { ETC2 fallback } \\
\text { Build System } \\
\text { Export Project } \\
\text { Run Device } \\
\text { Development Build } \\
\text { Autoconnect Profiler } \\
\text { Script Debugging }\end{array}$} & \multirow{3}{*}{\begin{tabular}{|l|} 
Don't override \\
32-bit \\
Gradle \\
\end{tabular}} & \multicolumn{2}{|l|}{ other Settings } \\
\hline DS & & & & \multicolumn{2}{|l|}{ Publishing Settings } \\
\hline & & & & XR Settings & \\
\hline tr tvos & & & All compatible $d i \oplus$ Refresh & Virtual Reality Supported & $\checkmark$ \\
\hline & & & $\square$ & Virtual Reality SDKs & \\
\hline (1) Xbox One & & & $\square$ & $=$ Cardboard & \\
\hline
\end{tabular}

Fig. 8. Setting Visual Control on Unity3D

Figure 8 shows visual control programming using commands on the mouse to find out the direction of the view. In the Unity3D application there is a feature to make an application virtual reality. This can change the mouse movement into an android movement by reading the gyro sensor. Gyro sensor readings on Android will be automatically read when the program is opened, by activating supported virtual reality when compiling. Then the application found on Android will be detected as a virtual reality application so that it will automatically use a gyro sensor to detect movements that are adjusted to the movement in the virtual laboratory.

In visual control, programming is almost the same as driving control. What distinguishes it is the data that is read in the virtual laboratory which on the drive is data from the cursor on the bluetooth remote that is moved to the right or left up or down. While in visual control, the data that is read is a gyro sensor on an android device that detects head movements when looking in various directions. The working system of visual control can be seen in Figure 9.

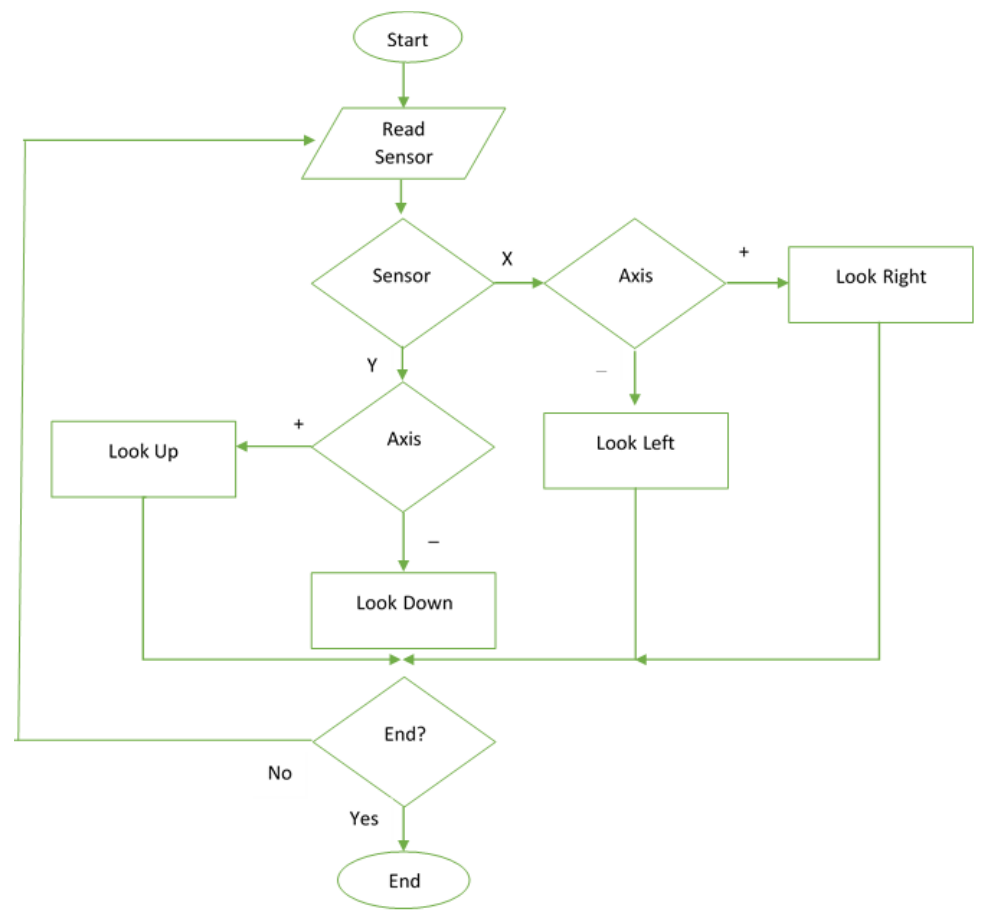

Fig. 9. Visual Control Flowchart 
The third is Command Control - to open / view / activate a command according to certain objects and certain commands. To control commands in the virtual laboratory, the main benchmark is at the midpoint on the screen or the user's view. The command is given by pressing the ok button on the remote with the navigation direction from the middle of the screen. In the virtual laboratory some objects that can be given a command are indicated by changing the midpoint on the screen into a circle. In Figure 10, a change in the midpoint of the screen shows that an object in the virtual laboratory can be given a command. The following is a program that is used to give commands through the midpoint of the screen or view.

On command control. Some objects that can be ordered can be known by changing the midpoint in the view. These objects are ICs and computers contained on the table. Some objects display a display in the form of information and IC characteristics on IC objects in Figure 11. Simulation of IC and digital circuit simulator command can be seen in Figure 12 and Figure 13 respectively.

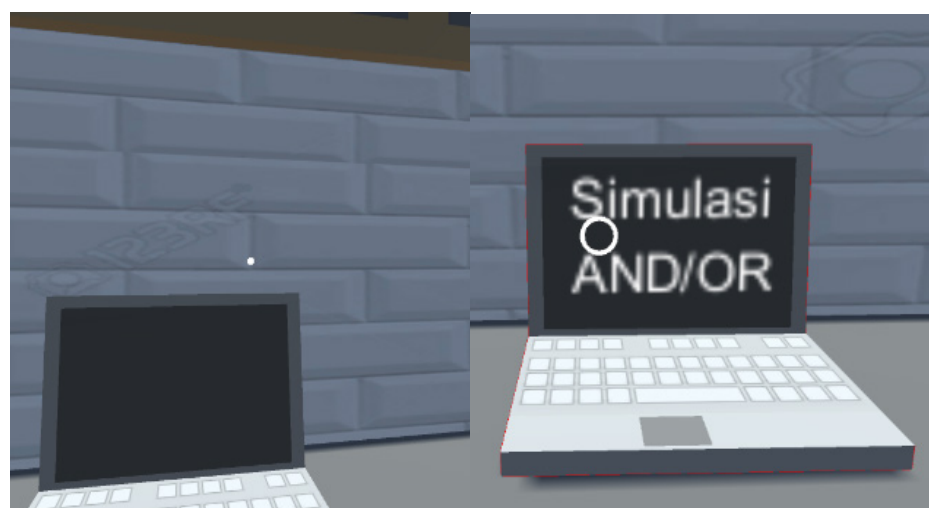

Fig. 10.Change Point that Shows

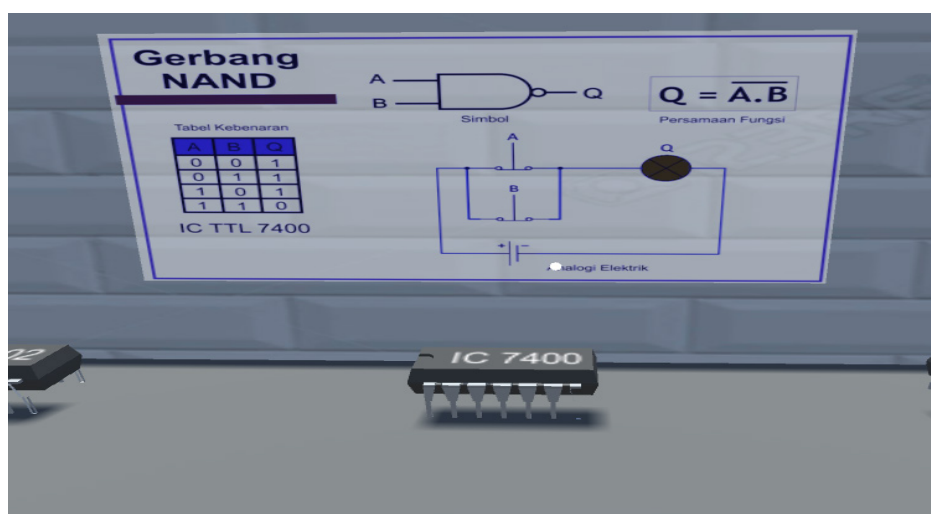

Fig. 11. IC Gate Characteristic Command 


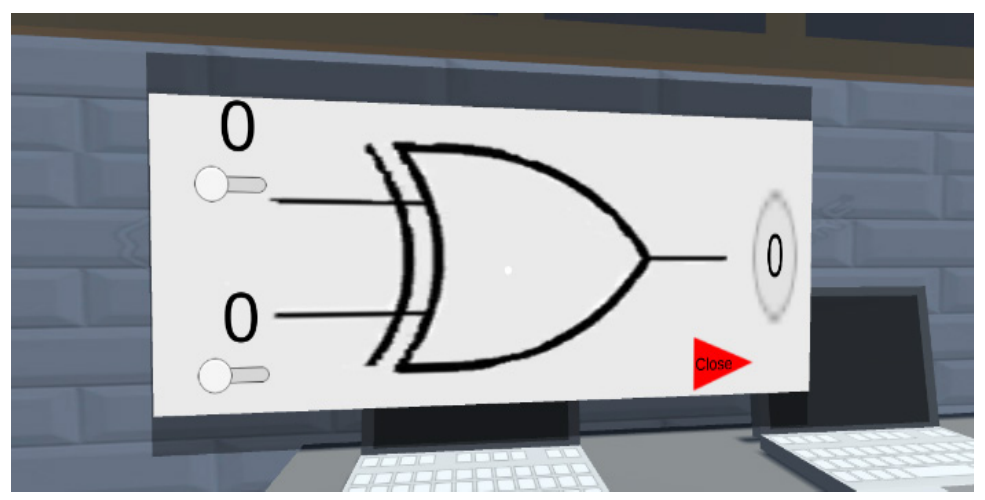

Fig. 12. IC Gate Simulator Commands

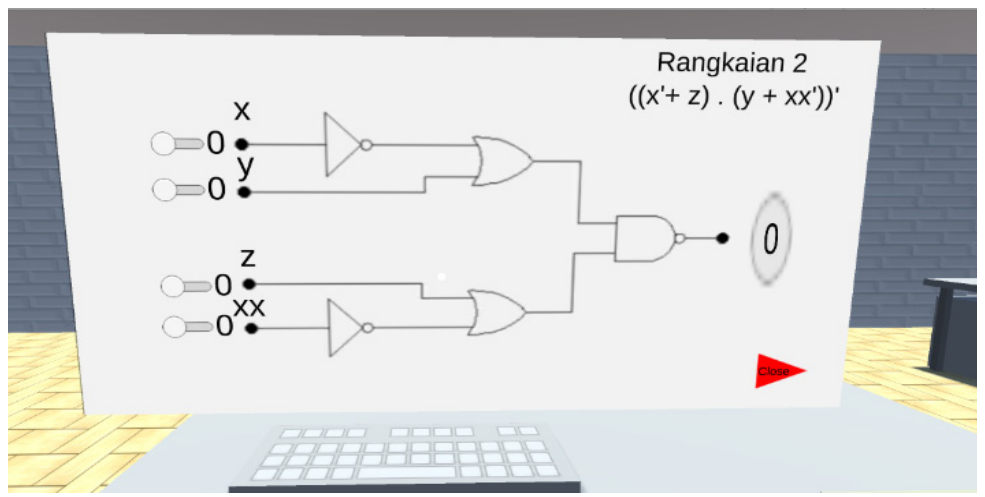

Fig. 13.The Digital Circuit Simulator Command

In the form of IC there are several choices of IC in the virtual reality display. The IC is IC AND, OR, NAND, NOR, XOR, and NOT. The IC displays a description of the nature of the IC gate, the IC gate symbol and the circuit on the IC gate usage. In addition to displaying the display, it needs to be pressed on the IC used and to serve it, it needs to be pressed again on the IC that was pressed before. Programs that are used to display and eliminate are programs that function to eliminate and bring up certain views that have been created and hidden. For the default display, the menu display is hidden. So you need a command by pressing the IC to display the description menu and the nature of the IC, this case can be seen in Figure 11.

Each IC in a digital laboratory has a digital technique of its own characteristics and can be distinguished based on the IC number found on the top of the IC. There are 6 types of ICs that are provided with different types of series and functions of the IC. IC information will appear when the center point on the screen when using VR is pressed when directed at the IC. When the midpoint is about the IC, the midpoint will change to a circle indicating that the IC is ready to take orders or click. Each click from each IC will display a series of images, Boolean algebra, and the truth table of the IC. Each 
IC has a different appearance for each type. The display can be removed or returned by pressing the IC again.

For the IC Gate Simulator display there are six IC simulators, namely NOT, AND, OR, NAND, NOR, XOR. Algorithms on ICs use IF commands. The use of algorithms used in each IC varies according to the nature of the IC. Setting input values 1 and 0 or $\mathrm{ON}$ and OFF is done by pressing the input button on the display and for removing the display by pressing the red close button. In some simulations there are two simulations in one view. For example AND and OR, to change the display between AND and OR, you must press the button on the top right so you can change the appearance of the simulation that has been opened.

In the logic gate simulation the user is given the flexibility to interact with the simulation display. The simulation display can be opened by pressing the laptop contained on the table in the digital engineering virtual laboratory. When the laptop is directed to the center point, the center point will change to a circle and what kind of gate simulation will appear that can be opened on the laptop.

There are several laptops in a digital engineering virtual laboratory. Each laptop displays NOT Gate, AND / OR Gate, NAND / NOR Gate, and X-OR Gate. Users can choose the logic gate on 1 laptop that has 2 types of gates. In this logic gate simulation the user can change the input from each input logic gate and the output will automatically emerge from the logic of the logic gate. Users can also replace logic gates of different types on certain laptops that provide a choice of logic gates. To close the logic gate simulation, it can be done by directing the center point in the digital engineering virtual lab towards the red sign in the lower right corner. If the midpoint has approached or reaches the red color, the midpoint will turn into a circle and ready to be closed or hidden again.

In the digital circuit simulation there are nine types of digital engineering simulation circuits that can be tried and practiced. The circuit has different functions and results according to the input of each circuit. Each circuit has a different algorithm and is programmed according to the circuit and logic gate used. The circuit can also be calculated manually using Boolean algebra because at the top right of each digital circuit simulation there is a Boolean algebra value from the circuit. Every computer has a set of simulation works.

\section{Conclusion}

Virtual digital engineering laboratories use virtualrreality technology to improve display quality and take advantage of technological advancements. Through a virtual laboratory using an Android smartphone device to open a virtual laboratory application. The supporting devices used are VR Box and VR controller which are used as controllers of virtual laboratories. In a virtual laboratory there are various items that resemble original items, some items have certain command functions that can be used and can display a certain display. The development of virtual laboratories uses Unity3D devices and can be further developed. Virtual laboratories provide knowledge of basic digital techniques in the form of IC characteristics, Logic Gate simulations, and digital circuit 
simulations. Virtual laboratory digital techniques have a variety of interactive functions found in the use of virtual laboratories. In addition to displaying theories from a lot of logic gates IC. Users can also provide input as desired and produce different outputs for each user. The logic used in the simulation is the same as the logic used in logic gates with properties that are compatible with logic gates. The use of VR by using Unity3D also provides convenience in accessing and adjusting the virtual laboratory as needed. Virtual laboratory digital techniques can also save costs if there are additional equipment and components from the virtual laboratory.

\section{$5 \quad$ References}

[1] Khalid Salmi, Hamid Magrez, Hanane Sefraoui, Abdelhak Ziyyat, (2019) Development of a Mobile Application for TeachingTransmission Line Theory, International Journal of Interactive Mobile Technologies (iJIM) - Vol. 13, No. 2, 2019

[2] Almarshoud, A, F. (2011). The advancement in using remote laboratories in electrical engineering education: a review. European Journal of Engineering Education, Vol. 35(5). 425-433.J. Clerk Maxwell, A Treatise on Electricity and Magnetism, 3rd ed., vol. 2. Oxford: Clarendon, 1892, pp.68 - 73.

[3] Mekonnen E. (2004). Health Laboratory Management and Quality Assurance. Ethiopia: Gondar University College.K. Elissa, "Title of paper if known," unpublished.

[4] WHO. (2011). Laboratory Quality Management System. France: WHO

[5] Education Bureau. (2013). Safety in Science Laboratories.

[6] PramuditaBudiastuti, M. Khairudin, M.N.A Azman. (2018). E-Instructional Multimedia in Basic Concepts of Electrical and Electronic Lessons, a. JurnalPendidikanTeknologidanKejuruan, Vol.24 (2). 262-269.

[7] A.K. Triatmaja and M. Khairudin. (2018) Study on Skill Improvement of Digital Electronics Using Virtual Laboratory with Mobile Virtual Reality. Proceeding of International Conference of Electrical, Electronics, Informatics and Vocational Education, Yogyakarta, Indonesia, 13 September 2018. https://doi.org/10.1088/1742-6596/1140/1/012021

[8] Persson, V. \&Nouri, J. (2018) A Systematic Review of Second Language Learning with Mobile Technologies. International Journal of Emerging Technologies in Learning. Vol. 13 (2), 53 - 61. https://doi.org/10.3991/ijet.v13i02.8094

[9] Zhang, M., Zhang, Z., Chang, Y., Aziz, E., \&Chassapis, C. (2018). Recent Developments in Game-Based Virtual Reality Educational Laboratories Using the Microsoft Kinect. International Journal of Emerging Technologies in Learning. Vol. 13(1), 138 - 159. https://doi.org/10.3991/ijet.v13i01.7773

[10] Gede Thadeo Angga Kusuma, I Made Agus Wirawan, I Ketut Resika Arthana, (2018) Virtual Reality for Learning Fish Types in Kindergarten, International Journal of Interactive Mobile Technologies (iJIM) - Vol. 12, No. 8, 2018.

[11] Odeh, S., Shanab, S, A., \&Anabtawi, M. (2015). Augmented Reality Internet Labs versus its Traditional and Virtual Equivalence. International Journal of Emerging Technologies in Learning. Vol. 10 (Issue 3), 4 - 9. https://doi.org/10.3991/ijet.v10i3.4354

[12] Hendra Pradibta, (2018) Augmented Reality: Daily Prayers for Preschooler Student, International Journal of Interactive Mobile Technologies (iJIM) - Vol. 12, No. 1, 2018. https://doi.org/10.3991/ijim.v12i1.7269 
[13] Lixia, Z. \&Guangran, L. (2009). Study and Design of 3D Virtual Scenes of Virtual Laboratory. International Conference on Computational Intelligence and Security, 11 - 14 December 2009, Beijing, China.

[14] Hendra Jaya, SaptoHaryoko, Lu'muLu'mu. (2017). Collaborative Learning for Children with Special Needs through Computer Supported Collaborative Learning at Vocational High Schools. JurnalPendidikanTeknologidanKejuruan, Vol 23, No 4.

[15] Dyrberg, N, R., Treusch, A, H., \&Wiegand, C. (2016). Virtual laboratories in science education: Students Motivation and Experiences in Two Tertiary Biology Courses. Journal of Biological Education. Vol.51 (4), $358 \quad$ - 374 . https://doi.org/10.1 $\underline{080 / 00219266.2016 .1257498}$

[16] Ogungbenro, O, U., Chukwudebe, G, A., Opara, F, K., \&Ezeh, G, N. (2017). Design and Implementation of Logic Gate Emulator. 3rd International Conference on Electro Technology for National Development, 7 - 10 November 2017, Owerri, Nigeria

\section{Authors}

Moh. Khairudin received his bachelor from Universitas Negeri Yogyakarta-Indonesia at the department of electrical engineering in 2002. He graduated from Institute Teknologi Sepuluh Nopember (ITS)-Indonesia with M. Eng in control electrical engineering in the year of 2004 and completed his $\mathrm{PhD}$ in control electrical engineering in the year of 2012, from Universiti Teknologi Malaysia, Johor, Malaysia. His research interested in the area of Flexible Manipulator, Robotics and Automation, Robust Control and Intelligent Control System.

Adhi Kurnia Triatmaja is a master student at the department of electrical engineering education, graduated school of Universitas Negeri Yogyakarta-Indonesia. His master thesis in the title of virtual laboratorium for the digital engineering.

Istanto Wahyu Djatmiko received his bachelor from Universitas Negeri Yogyakarta-Indonesia at the department of electrical engineering. His master and doctoral degree from the department of vocational education and training in the Universitas Negeri Yogyakarta-Indonesia. Now he is a head of department for master degree of electrical engineering education-Universitas Negeri Yogyakarta. His research interested in the area of human resources development for the teacher enhancement.

M.N.A. Azman is a Senior Lecturer, $\mathrm{PhD}$ at the Faculty of Technical and Vocational, Universiti Pendidikan Sultan Idris. He is the author, co-author and editor of several books or book chapters on Industrialized Building System (IBS) as well as published more than 50 scientific papers. Research interests focus on the study of Industrialised Building System (IBS), Precast Manufacturing Plant, Spatial Site Selection and Technical and Vocational Education and Training (TVET).

Article submitted 2019-02-12. Resubmitted 2019-03-17. Final acceptance 2019-03-17. Final version published as submitted by the authors. 